\title{
The Implications of Global Priorities for Biodiversity and Ecosystem Services Associated with Protected Areas
}

\author{
Christopher R. Pyke ${ }^{1}$
}

\begin{abstract}
Map-based prioritization systems have become ubiquitous tools for allocating resources for biological conservation. Although the scientific basis for these systems continues to be debated, they have become a significant factor in international conservation. A recent study found that published conservation priorities are associated with over one third of conservation spending by major international nongovernmental organizations totaling over $\$ 1.5 \times 10^{9}$ in 2002 alone. The growing influence of these systems on the allocation of resources for conservation underscores the need to understand their ecological and environmental implications. This paper addresses the role of global priorities in contributing to the future of land protection by considering three key questions: (1) What are the implications of business-asusual growth in land protection for the representation of biodiversity, i.e., the absence of priorities? (2) Would implementing global conservation prioritization systems change trends in biodiversity representation, i.e., conservation following priorities? (3) What are the implications of priority systemguided protected area growth for ecosystem services beyond biodiversity representation, i.e., nontarget consequences of implementation? These questions are addressed with analyses of information from the World Database for Protected Areas and the Global Gap Analysis. The results indicate that business-asusual growth in land protection will fill gaps slowly, most likely at a rate equivalent to chance. Following global priority systems would accelerate conservation of unprotected biodiversity, gap species; however, achieving these gains would exacerbate the current highly uneven global distribution of protected areas. The majority of areas targeted by priority systems already have above average levels of protection and additions following global priority systems would encourage growth in these already above average countries. Over time, these patterns could contribute to uneven distributions of important ecosystem services. This observation does not detract from the value of global priority systems for biodiversity conservation, but it does highlight their limitations and suggest the need for more comprehensive approaches to planning and prioritizing future land protection.
\end{abstract}

Key Words: hotspots; land use; priority areas; protected areas; systematic conservation planning, reserve design.

\section{INTRODUCTION}

At the turn of the 20th century, protected areas were oddities established in obscure, scenic corners of wilderness. Today, protected areas are a pervasive global land use covering $11.5 \%$ of the Earth's surface (Chape et al. 2005). The term protected areas encompasses a broad set of land uses ranging from near complete exclusion of human activities, e.g., zapovedniks in Russia, to intensively managed multiple use lands, e.g., sustainable forest districts in Brazil. Protected area growth over the last century has followed the exponential pattern typical of other global changes, e.g., population, water use, tropical deforestation, and the average increase exceeded $2 \%$ of a country's total land area between 1990 and 2002 (Fig. 1) (Steffen et al. 2003). Designated protected areas far exceed the roughly 1 to $3 \%$ of land used for urban settlement and rival the global extent of land uses such as grazing, forestry, and intensive agriculture (Center for International Earth Science Information Network 2004).

There are strong indicators that the global growth of protected areas will continue. Individual countries have made ambitious commitments to 
Fig. 1. Global growth of protected areas since 1900. The dashed line illustrates a fitted exponential curve. The establishment of Yellowstone National Park in 1872 marked the beginning of development of the now-traditional concept of protected areas, i.e., the withdrawal of land from settlement, occupancy, or sale for the benefit and enjoyment of people.

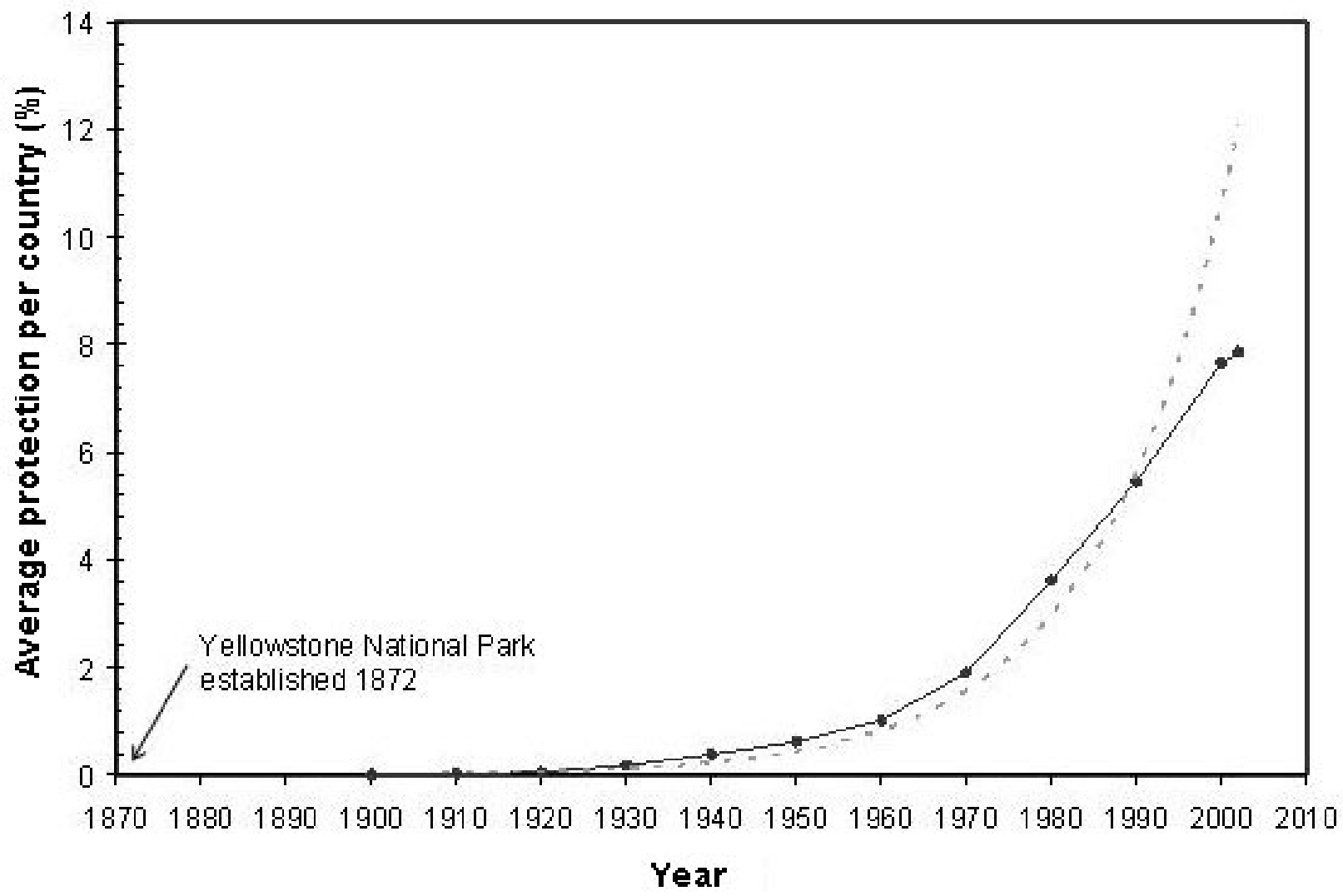

establish new protected areas, e.g., new commitments of $200,000 \mathrm{~km}^{2}$ at the Vth World Parks Congress, in Durban, South Africa, and, in many cases, they have earmarked substantial financial resources to realize these goals. These aspirations are supported by a mature set of global institutions, substantial pools of governmental and philanthropic assistance, and a growing body of scientific expertise (IUCN 2005). However, we understand very little about where, why, and how this growth is likely to take place. I consider three key questions: (1) What are the implications of business-as-usual growth in land protection for the representation of biodiversity? (2) Can global conservation prioritization systems change trends in biodiversity representation? (3) What are the implications of protected area growth for ecosystem services beyond biodiversity representation?

\section{BUSINESS-AS-USUAL TRAJECTORY}

Existing protected areas provide uneven representation of major habitat types and physiographic conditions (Hoekstra et al. 2005). These biases are reflected in strong spatial patterns across multiple scales, e.g., the ubiquitous preference for the protection of low productivity areas, such as rock and ice (Scott et al. 2001b, Hazen and Anthamatten 2004). These land use patterns lead to inconsistent levels of protection 
for biodiversity and so-called protection "gaps." Gaps are instances where species do not occur in any protected area across their range (Brooks et al. 2004, Rodrigues et al. 2004). Avoiding such biodiversity gaps has been promoted as a basic function for the protected area networks (Scott et al. 1993).

Given the rapid growth and well-known limitations of the current global protected area system, we should consider the implications of continued growth following the geographic patterns observed during the last decade: a "business-as-usual" trajectory. I used the World Database on Protected Areas to estimate per country land protection growth rates for the period of 1990-2002 (Fig. 2). I compared the country-level growth rates with independent data on the number of globally unprotected species occurring within a country from global gap analysis project. I found that relative rates of protected area growth were not significantly different between countries with different numbers of unprotected species. Protected areas with above average numbers of gap species grew at $2.1 \%$ / decade, while those with below average numbers of unprotected species grew at $1.7 \%$ /decade (data for 1990 to 2002). These averages are not significantly different (Wilcoxon rank-sum test, $Z=-1.2, P=$ 0.2 ), and they suggest that a business-as-usual trajectory would fill gaps and nongaps at similar rates. This would represent progress, albeit slower and less efficient than many stakeholders would prefer.

\section{UNDERSTANDING THE TRAJECTORY}

Given the limitations of the business-as-usual trajectory, the question is whether we know enough about the establishment of protected areas to understand the likelihood that these patterns will continue or to devise strategies for intentionally changing the trajectory in the future. Models of the establishment and spread of urban and agricultural land uses are widely available (Clarke and Gaydos 1998, Lambin et al. 2000). Unfortunately, land protection has not received the attention given to other land uses, so there are no equivalent resources for understanding past patterns or predicting future activity. Analyses for the United States suggest that the likelihood of protection has historically been inversely related to the productivity or potential economic value of the land (Scott et al. 2001a). Equivalent studies are not readily available for other parts of the world, but inspection of global maps of protected areas suggest that such a conclusion is at least reasonable hypothesis.

A number of statistical analyses have been conducted to investigate correlates of more recent land protection. Again, some of the best information about decision making is available for the United States, and where public spending on land protection has been significantly related to measures of class, race, education, wealth, and population density (Romero and Liserio 2002, HowellMoroney 2004). Internationally, only the most general relationships between economic activity and land protection have been explored, such as considering land protection with respect to expectations from an Environmental Kuznet Curve (EKC). The original EKC concept is based on intercountry comparisons suggesting an inverted Ushaped relationship between economic development and environmental protection, in this case measured by the extent of land protection (Van 2003). This argument parallels observations from the United States, indicating that wealth, population pressure, and societal values all contribute to the likelihood of investment in land protection. Increases in all of these factors suggest that land protection will continue, and potentially accelerate over the decades, i.e., more relatively wealthy people living in higher density situations. However, the decentralized, multifaceted nature of land protection decision making also suggests that it is a difficult process to manage or optimize (Theobald and Hobbs 2002).

\section{CHANGING TRAJECTORIES}

Several international nongovernmental organizations (NGOs) believe that they can change the trajectory of land protection, not by making changes in established social or economic drivers, but by setting geographic conservation priorities. The idea is that relatively small investments in priority setting can focus attention on specific places and generate disproportionate responses from the international community, i.e., allocation of attention, effort, or financial resources (Brooks et al. 2006). On the ground, the resulting conservation actions take a variety of forms, including the designation of new protected areas (Balmford et al. 2003). Despite the emphasis on these priorities in the current literature, 
Fig. 2. Frequency distribution of protected area growth rates for the period 1990-2000.

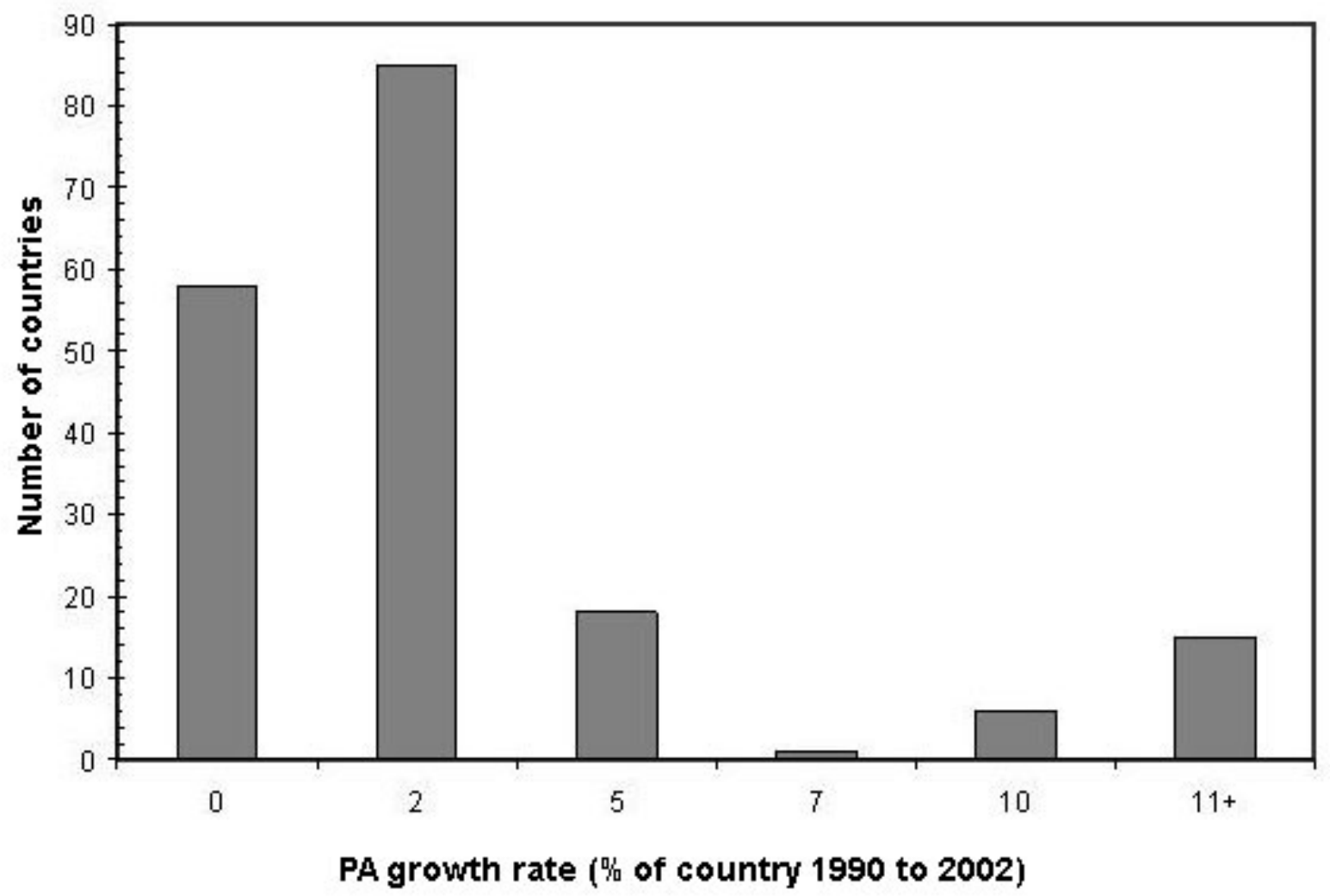

it is hard to evaluate their role in the historic evolution of land protection or predict their impact on its future trajectory (Myers et al. 2000, Meir et al. 2004, Orme et al. 2005). Geographic priorities have not been identified as a significant driver of land protection in recent statistical analyses, nor is there substantial theory about their relative importance. However, anecdotal evidence suggests that priorities can motivate action. For example, the widely quoted goal of allocating $10 \%$ of land areas to conservation was perceived as an important conservation benchmark (Soule and Sanjayan 1998). Beyond such basic inferences, there appears to be little except assumptions, hope, and intuition.

Conservation International (CI), Birdlife International (BI), and World Wildlife Fund (WWF) have published and promoted map-based prioritization systems (Olson and Dinerstein 1998, Myers et al. 2000, BI 2004). These NGOs claim that their geographic priorities provide guidance for future investment (Olson and Dinerstein 1998) or even represent "silver bullet" conservation strategies (Myers et al. 2000). These systems are designed to direct work by the organization that created them, and, more importantly, encourage investment by other organizations. Recent research suggests that in addition to directing spending by their own organization, these global priorities are correlated with up to $33 \%$ of global conservation spending by other major international organizations that do not publish their own geographic priorities, e.g., The World Bank, Global Environmental Facility (Halpern et al. 2006). In 2002, this may have resulted in up to $\$ 400$ million in extra spending on areas identified by the prioritizing NGOs. Information about NGO spending is very limited, and the fraction of funds spent on the designation of new protected areas is unknown. 
The potential importance of these priorities and the resulting flows of resources suggest the need to consider the consequences of following one or more global priority systems for future patterns of land protection. Again, I used the global gap dataset, and this time I compared biodiversity gaps to a set of independently derived global priorities set by CI (Hotspots), BI (Important Bird Areas), and WWF (Global 200). I also used a composite priority map representing areas identified by all three organizations, a.k.a., census priorities (Halpern et al. 2006). Countries identified as "global priorities" contain many more gap species than nonprioritized countries (Table 1). This result holds for any single prioritization system, as well as the subset of area prioritized by all three. Following any one or some combination of these prioritization systems would fill gaps in biodiversity protection much more quickly than the business-as-usual scenario.

\section{IMPLICATIONS FOR NONBIODIVERSITY ECOSYSTEM SERVICES}

By design, existing conservation prioritization systems emphasize the efficiency of relatively small geographic areas for representing sets of threatened biodiversity elements, such as species in the case of CI's hotspots. The goal of these approaches is to minimize some concept of cost or conflict by reducing the total area prioritized; however, it has been pointed out that geographic area is often a poor proxy for actual conservation costs or potential conflict (Wilson et al. 2006). This can be an important goal, but biodiversity representation is only one ecosystem service provided by protected areas. Many ecosystem services do not follow the same global patterns, and some services must be produced and consumed locally (Orme et al. 2005). Common examples of such ecosystem services include water supply, water quality, aesthetics, recreational opportunities, and cultural and historical preservation (Luck et al. 2003, Kremen 2005). Although the geography of ecosystem services is much more poorly understood than species biogeography, research suggests that the spatial and temporal distribution of ecosystem services is important for human activities such as agriculture (Horner-Devine et al. 2003). At the very least, it is important to recognize that the specific conservation target, e.g., biodiversity vs. nondiversity services, will play a key role in determining which lands are prioritized. This should be a concern when considering strategies for identifying and designating protected areas, since, in practice, protected areas are almost always serve multiple environmental functions.

The existing network of global protected areas is unevenly distributed with respect to key ecosystem services (Tewksbury et al. 2002). Currently, a few countries have extensive protected areas, whereas many others protect only relatively small areas (Fig. $3)$. This observation alone is not necessarily diagnostic of a problem. This could be an efficient pattern with respect to some social or economic objective. However, the existing network fails to protect many elements of biodiversity and key ecosystem services, and there is no obvious reason for such large variance in human needs for basic ecosystem services associated with protected areas, e.g., clean air, potable water. Of course, these services are also provided outside of protected areas, but in many places, protected natural areas provide a core set of ecosystem functions, e.g., a green infrastructure (Walmsley 2006). The current global distribution of protected areas reflects the designation of relatively large percentages of terrestrial land bases by some countries and the relative scarcity of protected areas in others. Countries with extensive protected areas experience opportunity costs associated with the loss of land for other uses, e.g., intensive development, while they receive benefits such as profits from ecotourism, recreation, and ecosystem services. Countries that do not designate protected areas may jeopardize the local provision of ecosystem services, while benefiting from the regional or global ecosystem services provided by protected areas in other countries. At the moment, we lack even the most basic data required to understand these trade-offs and long-term social, economic, and environmental consequences of these choices.

Future growth in protected areas could help provide a more even distribution of protection for ecosystem services. I considered this by evaluating the direction of changes in the international evenness of land protection associated with the implementation of the Nongovernmental organization (NG0) global priority systems. I analyzed changes in distribution by scoring all countries based on the absolute value of their current protection as a deviation below the global average; a score I call an evenness shortfall score (ESS). Countries at or above the global average received an ESS of 0 and countries with no protected areas received an ESS of 10. I evaluated 
Fig. 3. Frequency distribution of land protection for 183 countries. The per country average is $7.9 \%$, compromising $11.5 \%$ of the global terrestrial land area (Chape et al. 2005).

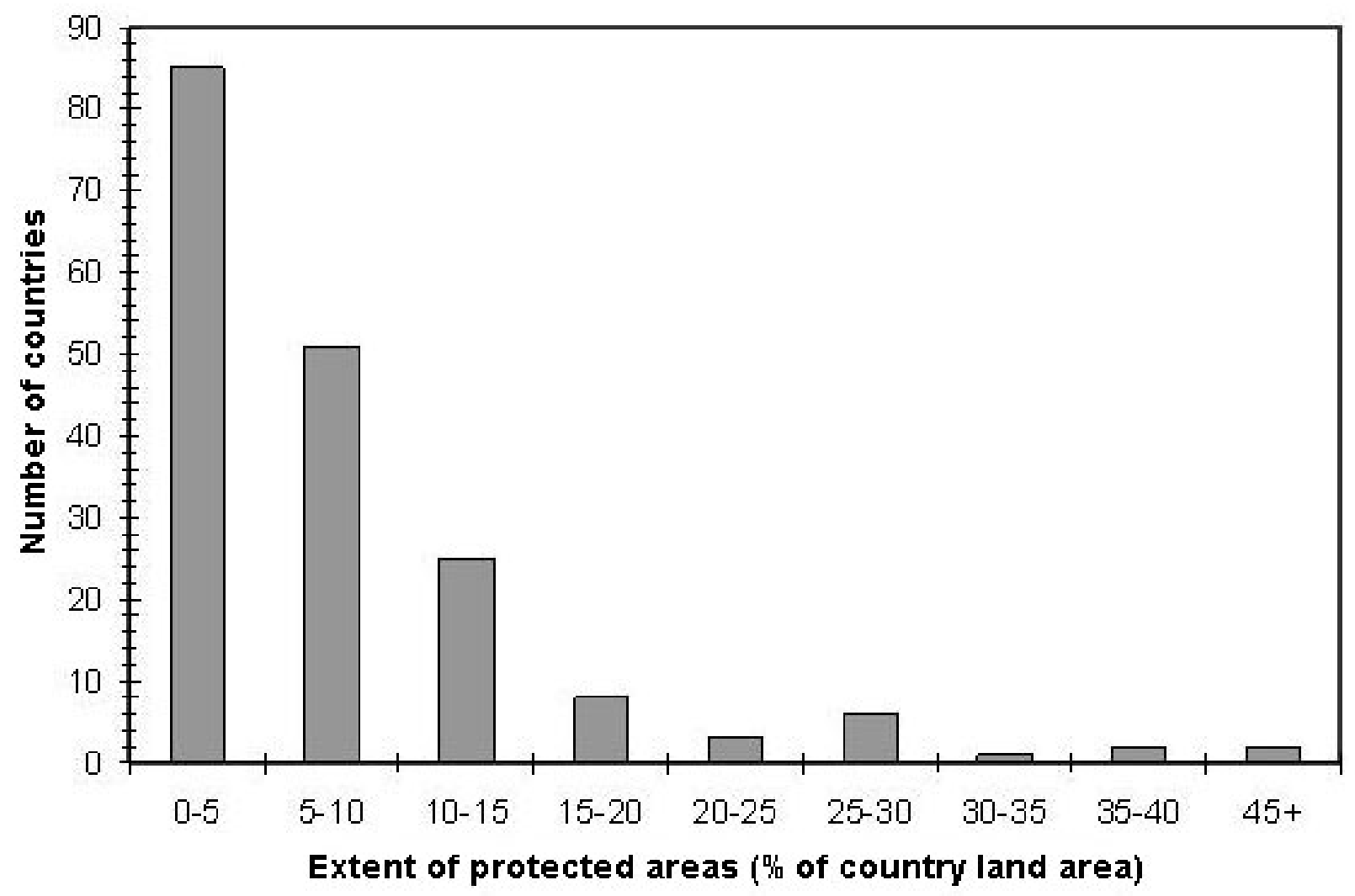

scores for countries with and without NGO priority designation. I found that scores for nonprioritized countries were equal to or greater than prioritized countries (Table 1). This indicates that countries identified as global priorities already have higher than average levels of land protection. Adding additional protected areas to these countries without equal or greater additions to nonprioritized countries will exacerbate the current distribution, $i$. e., compound the skewed distribution of protected areas between countries. This suggests that NGO global prioritization systems are not likely to contribute to improving the evenness of global land protection.

This is a logical consequence of the philosophy underlying these prioritization systems. The goal of minimizing prioritized area and maximizing representation for targets naturally concentrates effort. This tendency can be balanced by stratification approaches that require objectives to be met for multiple sub-regions or thematic divisions, e.g., conservation goals are set for each habitat type within each ecoregion (Groves 2003, Pyke and Fischer 2005). This approach inevitably increases the area required to meet biodiversity goals, while spreading out the geographic distribution of priorities. The resulting patterns determine the winners and losers in the prioritization processes, and, consequently, patterns of political support and opposition (Solecki et al. 2004).

In theory, it is possible to find efficient land protection strategies that maximize both species representation and ecosystem services. However, in 
Table 1. Number species/country identified by the Global Gap assessment for nonprioritized and prioritized countries. Significant differences between nonprioritized and prioritized countries are indicated by $*$ for $P<0.1$ and $* *$ for $P<0.01$ (Wilcoxon rank-sum test).

\begin{tabular}{|c|c|c|c|c|}
\hline \multirow[b]{2}{*}{ Priority system } & \multicolumn{2}{|c|}{ Species representation } & \multicolumn{2}{|c|}{ Equity shortfall scores } \\
\hline & $\begin{array}{c}\text { Gap species/ } \\
\text { nonprioritized countries }\end{array}$ & $\begin{array}{l}\text { Gap species/ } \\
\text { prioritized countries }\end{array}$ & $\begin{array}{l}\text { ESS/ } \\
\text { nonprioritized countries }\end{array}$ & $\begin{array}{l}\text { ESS/ } \\
\text { prioritized countries }\end{array}$ \\
\hline Consensus & 1.0 & $21.8 * *$ & 3.2 & $2.5 *$ \\
\hline Global 200 & 0.3 & $9.9 * *$ & 4.4 & $2.5 * *$ \\
\hline Hotspots & 1.8 & $13.0 * *$ & 3.0 & 2.9 \\
\hline Important Bird Areas & 1.4 & $14.7 * *$ & 2.9 & 2.9 \\
\hline
\end{tabular}

practice, our limited understanding of the geography of ecosystem services currently makes this difficult. It is possible to describe a theoretical frontier between species representation and the provision of ecosystem services, but it is difficult to meaningfully parameterize the ecosystem services dimension, particularly at regional and global scales. Even if this could be accomplished, it is not clear how to quantify trade-offs between competing ecosystem services, such the protection of an imperiled species and provision clean water. A more even distribution of land protection between countries would be a rudimentary proxy for this complex relationship and practical step in the right direction.

\section{CONCLUSIONS}

The establishment of protected areas is the most basic and widespread conservation strategy (Balmford et al. 2002). Many practitioners and researchers have noted that traditional, highly restrictive protected areas alone are not sufficient, and it essential to recognize the importance of privately and communally owned lands. In response, the conservation community has diversified and expanded its approaches to include ever more creative and nuanced land protection strategies. Many of contemporary approaches are far from the traditional notion of building a wall or a fence around a collection of threatened resources The success of these strategies has made protected areas a globally important land use and an essential part of human-dominated landscapes. However, the recent trajectory of business-as-usual land protection will not close existing biodiversity gaps or provide more even protection for ecosystem services. The primary drivers of the establishment of protected areas, like other land uses, are social and economic processes. Most of these processes are difficult to influence; however, international nongovernmental organizations (NGOs) have set thematic and geographic priorities that attempt to change the future trajectory of land protection by setting geographic conservation priorities. Adding protected areas in regions identified by existing conservation prioritization systems will improve on the business-as-usual trajectory by making it more likely new protected areas will fill biodiversity gaps. However, these priorities are not comprehensive road maps. Implementing them in isolation could exacerbate existing biases and contribute to uneven distributions of ecosystem services. This observation does not detract from their potential value as guides for biodiversity conservation, but it does underscore the need for a comprehensive approach to planning, prioritizing, and financing future land protection based on a more complete understanding of land protection as a dynamic land use that provides multiple services. 
These interacting processes mean that future land protection cannot be forecast or shaped with great precision; rather, at best, it can be slowly guided toward new objectives. Efforts to prioritize land protection are analogous to the use of a rudder to turn a massive ocean going ship: a relatively small, but strategic, application of force can change the course of a massive object. Global conservation priorities attempt to act as a rudder by nudging conservation action toward more efficient and effective patterns. This perspective may not have the marketing appeal of hotspots or the analytical rigor of an optimal portfolio, but it better reflects the process of land protection and the realistic opportunities for conservation action.

Responses to this article can be read online at:

http://www.ecologyandsociety.org/voll2/iss 1/art4/responses/

\section{Acknowledgments:}

The author appreciated A. Rodrigues's help with access to the global gap analysis results and constructive comments from B. Bierwagen, $H$. Fox, B. Halpern, S. Andelman, and J. Hoesktra. The views expressed in this paper are the author's own and do not reflect policies of the U.S. Environmental Protection Agency.

\section{LITERATURE CITED}

Balmford, A., A. Bruner, P. Cooper, R. Costanza, S. Farber, R. E. Green, M. Jenkins, P. Jefferiss, V. Jessamy, J. Madden, K. Munro, N. Myers, S. Naeem, J. Paavola, M. Rayment, S. Rosendo, J. Roughgarden, K. Trumper, and R. K. Tuner. 2002. Economic reasons for conserving wild nature. Science 297:950-953.

Balmford, A., K. J. Gaston, S. Blyth, A. James, and V. Kapos. 2003. Global variation in terrestrial conservation costs, conservation benefits, and unmet conservation needs. Proceedings of the National Academy of Sciences 100:1046-1050.

Birdlife International (BI). 2004. BI, Important bird areas. 2004.

Brooks, T. M. M. I. Bakarr, T. Boucher, G. A. B. da Fonseca, C. Hilton-Taylor, J. M. Hoekstra, T. Moritz, S. Olivier, J. Parrish, R. L. Pressey, A. S. L. Rodriques, W. Sechrest, A. Stattersfield, W. Strahm, and S. N. Stuard. 2004. Coverage provided by the global protected-area system: Is it enough? Bioscience 54(12):1081-1091.

Brooks, T. M., R. A. Mittermeier, G. A. B. de Fonseca, J. Gerlach, M. Hoffman, J. F. Lamoreux, C. G. Mittermeier, J. D. Pilgrim, and A. S. L. Rodrigues. 2006. Global biodiversity conservation priorities. Science 313(5783):58-61.

Center for International Earth Science Information Network. 2004. GRUMP Volume 1., Columbia University and Centro Internacional de Agricultura Tropical (CIAT) Palisades, New York, USA.

S. Chape, J. Harrison, M. Spalding, and I. Lysenko. 2005. Measuring the extent and effectiveness of protected areas as an indicator for meeting global biodiversity targets. Philosophical Transactions of the Royal Society of London B Biological Sciences 360(1454):443-455.

Clarke, K. C., and L. J. Gaydos. 1998. Loosecoupling a cellular automaton model and GIS: longterm urban growth prediction for San Francisco and Washington/Baltimore. International Journal of Geographic Information Science 12(7):699-714.

Groves, C. 2003. Drafting a conservation blueprint: a practitioner's guide to planning for biodiversity. Island Press, Washington, D.C., USA.

Halpern, B. S., C. R. Pyke, H. E. Fox, J. C. Haney, M. A. Schlaepfer, and P. Zaradic. 2006. Gaps and mismatches between global conservation priorities and spending. Conservation Biology 20(1):56-64.

Hazen, H. D., and P. I. Anthamatten. 2004. Representation of ecological regions by protected areas at the global scale. Physical Geography 25 (6):499-512.

Hoekstra, J, M., T. M. Boucher, T. H. Ricketts, and C. Roberts . 2005. Confronting a biome crisis: global disparities of habitat loss and protection. Ecology Letters 8(1):23-29.

Horner-Devine, M. C., G. C. Daily, P. R. Ehrlich, and C. L. Boggs . 2003. Countryside biogeography of tropical butterflies. Conservation Biology 17 
(1):168-177.

Howell-Moroney, M. 2004. What are the determinants of open-space ballot measures? An extension of the research. Social Science Quarterly 85(1):169-79.

Kremen, C. 2005. Managing ecosystem services: what do we need to know about their ecology? Ecology Letters 8:468-79.

Lambin, E. F., M. D. A. Rounsevell, and H. J. Geist. 2000. Are agricultural land-use models able to predict changes in land-use intensity? Agriculture, Ecosystems and Environment $\mathbf{8 2}$ (1):321-31.

Luck, G. W., G. C. Daily, and P. Ehrlich. 2003. Population diversity and ecosystem services. Trends in Ecology and Evolution 18(7):331-336.

Meir, E, S. J. Andelman, and H. P. Possingham. 2004. Does conservation planning matter in a dynamic and uncertain world? Ecology Letters 11:615-622.

Myers, N, R. A. Mittermeier, C. G. Mittermeier, G. A. B. Fonseca, and J. Kent. 2000. Biodiversity hotspots for conservation priorities. Nature 40:853-858.

Olson, D. M., and E. Dinerstein. 1998. The global 200: a representation approach to conserving the Earth's most biologically valuable ecoregions. Conservation Biology 12:502-515.

Orme, C. D. L., R. G. Davies, M. Burgess, F. Eigenbrod, N. Pickup, V.A. Olson, A. J. Webster, T-S. Ding, P. C. Ras , R. S. Ridgely, A. J. Stattersfield, P. M. Bennett, T. M. Blackburn, K. J. Gaston, and I. P. F. Owens. 2005. Global hotspots of species richness are not congruent with endemism or threat. Nature 436:1016-1019.

Pyke, C. R., and D. T. Fischer. 2005. Selection of bioclimatically representative biological reserve systems under climatic change. Biological Conservation 121(3):429-41.

Rodrigues, A. S. L., S. J. Andelman, M. I. Bakarr, L. Boitani, T. M. Brooks, R. M. Cowling, L. D. C. Fishpool, G. A. B. da Fonseca, K. J. Gaston, M. Hoffmann, J. S. Long, P. A. Marquet, J. D. Pilgrim , R. L. Pressey, J. Schipper, W. Sechrest,
S. N. Stuart, L. G. Underhill, R. W. Waller, M. E. J. Watts, and X. Yan. 2004. Effectiveness of the global protected area network in representing species diversity. Nature 428(6983):640-643.

Romero, F, and A. Liserio. 2002. Saving open spaces: determinants of 1998 and 1999 "Antisprawl" ballot measures. Social Science Quarterly 83(1):341-352.

Scott, J. M., F. D. Davis, B. Csuti, R. Noss, B. Butterfield, C. Groves, H. Anderson, S. Caicco, F. D'Erchia, J. Edwards, J. Ulliman, and R. G. Wright. 1993. Gap analysis: a geographic approach to protection of biological diversity. Wildlife Monographs 123:.

Scott, J. M., F. W. Davis, R. G. McGhie, R. G. Wright, C. Groves, and J. Estes. 2001a. Nature reserves: do they capture the full range of America's biological diversity? Ecological Applications 11 (4):999-1007.

Scott, J. M., M. Murray, R. G. Wright, B. Csuti, P. Morgan, and R. L. Pressey. $2001 b$. Representation of natural vegetation in protected areas: capturing the geographic range. Biodiversity and Conservation 10:1297-1301.

Solecki, W. D., R. J. Mason, and S. Martin. 2004. The geography of support for open-space initiatives: a case study of New Jersey's 1998 ballot measure. Social Science Quarterly 85:624-639.

Soule, M. E., and M. A. Sanjayan. 1998. Conservation targets: do they help? Science 279:2060-2061.

Steffen, W, A. Sanderson, P. Tyson, J. Jager, P. Matson, B. Moore, III, F. Oldfield, K. Richardson, H. J. Schellnhuber, B. L. Turner, II, and R. Wasson. 2003. Global change and the Earth system: a planet under pressure. Springer-Verlag, Berlin, Germany..

Tewksbury, J. J., D. J. Levey, N. M. Haddad, S. Sargent, J. L. Orrock, A. Weldon, B. J. Danielson, F. J. Brinkerhof, E. I. Damschen, and P. Townsend. 2002. Corridors affect plants, animals, and their interactions in fragmented landscapes. Proceedings of the National Academy of Science 99 (20):12923-12926.

Theobald, D. M., and N. T. Hobbs. 2002. A 
framework for evaluating land use planning alternatives: protecting biodiversity on private land. Conservation Ecology 6(1):5.

Van, P. H. 2003. A semiparametric analysis of determinants of a protected area. Applied Economics Letters 10:661-665.

Walmsley A. 2006. Greenways: multiplying and diversifying in the 21st century. Landscape and Urban Planning 76(1-4):252-290.

Wilson, K. A., M. F. McBride, M. Bode, and H. P. Possingham. 2006. Prioritizing global conservation efforts. Nature 440(7082):337-340. 